\title{
The Role of Psychological Hardiness on Performance of Scissors Kick
}

\author{
M. Haluk Sivrikaya \\ Correspondence: M. Haluk Sivrikaya, Faculty of Sport Sciences, Ataturk University, Erzurum, Turkey. \\ Received: December 17, 2018 \\ doi:10.11114/jets.v6i12a.3932 \\ Accepted: January 2, 2019 \\ Online Published: January 3, 2019 \\ URL: https://doi.org/10.11114/jets.v6i12a.3932
}

\begin{abstract}
The main purpose of this study was to find the effect of psychological hardiness on performance of scissors kick in football. The present research was practical in terms of purpose and correlation in term of nature. The statistical population of research was Ataturk University female students (18-24 yrs old) unfamiliar to football scissors kick, in 2018. So, 28 participants were selected randomly based on Morgan Table from 30 vulenteers. In this study, two quastionnars of hardiness and Charbonneau sport performance were used to collect data. To test hypotheses, regression test was used. In this research, SPSS 20 software was used in all calculations and tests.The results showed that psychological hardiness play a significant role on performance of scissors kick. It is one of the most important characteristics of a successful athlete.
\end{abstract}

Keywords: psychological hardiness, athletic skills, scissors kick

\section{Introduction}

In the last few decades, sports psychology has become an important part of sport, especially as coaches are well-known and experienced before the time of the competition and during training and exercises. One of the applications of psychology in sport is to help improve performance, to learn and to execute more correctly and more easily the skills, using different techniques and techniques such as mental training, self-confidence and self-efficacy. Admittedly, these psychosocial skills are the main and most prominent components of continuous performance at high levels of competition (Newland et al., 2013).

The inability to work effectively with sports stress is detrimental to the athlete's performance (Stoeber, 2001). However, it seems that the effect of stress on performance depends on individual athletes' differences, because some players or coaches manage and manage more stressful and difficult situations than others.

Kobasa (1979) stated that the distinct responses of individuals to the same stressful events were a personality difference, the best described for it being psychological hardiness (Kobasa, 1979). Mental hardness is a practicing skill that helps you to deal with challenging situations. Psychic hardness is a comprehensive term that indicates the power of your mental games. The mental tenacity does not guarantee your victory, but it helps you to withstand the hard pressures and will allow you to take this opportunity to your success. Sport psychology defines mental tenacity as the athlete's ability to stay focused, stay motivated, committed to achieving goals, especially in confronting hardships and failures. It is not just the day of the game itself and you have it.

If mental hardiness is a skill, then it can be developed with technical and physical skills. According to Kobasa, the tenacity, restraint, and protection barrier is structured around three components of commitment, control and combat. Belief in commitment vs. self-alienation tends to be deeply involved in doing something. The committed people are no longer in high-stress situations. Control is the belief that events of life and their consequences are predictable and controlled. A person with a sense of control, anxiety and self-control, is more than luck, and believes that he can manage what is happening around him with his own efforts. Combatting is a belief that changes in natural life are perceived and positive perceptions of it are deduced (Ucan, 2018).

Skills to challenge the correct performance are called technique. Skill in the word means agility and mastery. Skill is one of the most controversial topics in the field of exercise and sports science. Human beings in the 21st century, in contrast to the past century, have more than ever been governed by their own virtues and the environment due to the advancement of technology, all of which, of course, owe the task of teaching and exercising different skills. Undoubtedly, the importance of implementing skills in human development is far beyond the perspective of his thoughts. Therefore, since the environment of human life is always subject to change, man has to perform skills to 
overcome these transformations. In this discussion, we will talk about the skills in the field of movement science and sports. Skill is one of the most controversial topics in the field of exercise and science of sport (Ucan, 2018).

Hardness is a practicing skill that helps you deal with challenging situations. Psychic hardness is a comprehensive term that indicates the power of your mental games. The mental tenacity does not guarantee your victory, but it helps you to withstand the hard pressures and will allow you to take this opportunity to your success. The importance of what may happen during a match and your calm and self-confidence fluctuate, such as the bad decisions of an arbitrator, and the importance of a high level of combat readiness for a combat athlete. Therefore, this issue is of paramount importance.

Mental toughness has been historically one of the most used but least understood terms in sport psychology. However, despite the apparent breadth of opinion, a general definitional consensus is emerging from the literature reflecting the cognitive-behavioural multivariate nature of the construct (Sheard, 2009).

The three hardiness characteristics amount to the existential courage that motivates athletes to work hard at transforming potentially stressful situations into opportunities. As such, hardiness is a pathway to resilience under stress, where performance is enhanced by active or decisive coping efforts in stressful situations. In addition to evidence from rugby league, and sport in general (Sheard \& Golby, 2006a), the positive influence of hardiness on performance has been reported in such diverse samples as human resource consultants and university undergraduate students (Sheard, Golby, 2007; Sheard, 2009).

According to WHO, fifty two million people of world are suffering from severe mental diseases and as many as 250 million people are grappling with mild diseases. Research based evidence suggest that there is a positive and significant relationship between the psychological hardness and mental health (Hasanvand et al., 2014).

Sheard (2009) revealed that the Australian Universities players had significantly higher mean scores on positive cognition, visualization, total mental toughness, and challenge than their opponents from Great Britain. The Australian Universities players were also the tournament winners. The findings concur with previous research indicating superior mental toughness and hardiness are related to successful sport performance. Practical implications focus on the potentiality of ameliorative cultural environments.

In a research by Sing (2010) it was revealed that athletic coaches were found to be signifi cantly younger, signifi cantly greater in control disposition of personality hardiness and having signifi cantly lesser amount of competition anxiety when compared with the wrestling coaches (Sing, 2010).

Hasanvand et al. (2014) revealed that there was a positive and significant relationship between mental health and emotional intelligence and its components (self-motivation, self-consciousness, self-control, social awareness, and social skills) with psychological hardiness. They believed that by promoting psychological hardiness through increasing mental health and emotional intelligence, we can overcome stressful and anxious factors, as well as factors resulting in most psychological problems.

Newland et al. (2013) found that among the firefighters, in addition to maintaining health, muscular analysis and heart disease, there were significant points, and there was a significant relationship between marital status and body mass. Hystad et al. (2012) confirmed the factors of tenacity by factor analysis and their meaningful positive relationships among male employees.

Thomson (2017) states that elite rugby players will increase their hardiness, their performance will increase. Also, stress control has increased stiffness and performance Lin et al. (2017) has shown that the stress level, depression and anxiety of individuals' decreases with increasing their hardiness. Due to the increasing severity of their mental health, their hardiness levels are close to their level of physical fitness.

Eris (2018) studied the effects of physical fitness and mental hardness on the performance of elite basketball players in Turkey. Physical fitness affected psychological characteristics and performance. Since their importance is clear to everybody, we need to plan to enhance their psychological and mental health.

Competitive conditions, stress to overcome challenges and optimal performance of sport have a negative effect on mental health of elite athletes. Lin et al. (2017) showed that personality traits lead to the use of problem-solving strategies, hardiness and mental health, and hardiness is a good predictor of mental health and performance.

Given the above, is it a question of how psychological hardiness role in the performance of sports skills of female footballers?

\section{Method}

In terms of purpose, the view was implemented as a descriptive (correlation) research. For analyzing the research data, regression correlation analysis was used. 


\subsection{Society and Sampling Method}

The statistical population of the study was all Ataturk University female students who vulenteerly participated in this study in number of 30 in 2018. By Morgan table 28 of them were randomly selected for this research.

\subsection{Collection Tool}

\subsubsection{Long and Gullet Hardiness Questionnaire (2001)}

One of the characteristics of personality that is stressed as a moderator is psychological hardiness, which means endurance, ability, and tolerance in difficult and difficult situations (Jafari et al., 2010). Hardness refers to the performance of a person based on cognitive assessment, and includes three components of commitment, control and struggle. The validity of this questionnaire is a self-report scale that consists of 42 questions and is developed by Long and Gollet (2001).

\subsubsection{Charbonneau Sports Performance Questionnaire}

The questionnaire was made in 2001 by Charbonneau. The questionnaire has five questions in the Likert scale and is designed to evaluate the performance of the athletes and is completed by the respective instructor for each athlete. The scores derived from the five questions show the final scores of the athlete's performance. This question is on a scale from 1 (very poorly) to 5 (very special) (Charbunio, Barbing and Kilwa, 2001). The scores derived from the five questions are summarized and the final score of the athlete's performance is obtained, which is the final score of the performance The athlete is in the range of 5 to 25 (at least up to the maximum), and the average of the reliability coefficients of this questionnaire is calculated by Charbono, 0.71 .

\subsection{Data Analysis Method}

In order to analyze the data obtained from the collected questionnaires, regression was used. In this research, 20SPSS software has been used in all calculations

\section{Results}

Frequency distribution and percentage of statistical sample are based on the age of the participants in Table 1 .

Table 1. Frequency distribution age of participants

\begin{tabular}{lcc}
\hline Age & F & Percent \\
\hline $18-20$ & 15 & \\
\hline $21-24$ & 13 & 100 \\
\hline Total & 28 & \\
\hline
\end{tabular}

As shown in Table 1, 15 participants were between 18-20 years old have 13 were 21-24 years old.

Table 2. Correlation between psychological hardiness and skill performance

\begin{tabular}{llcc}
\hline & & hardiness & Skill performance \\
\hline hardiness & Pearson correlation coefficient & 1 & 0.274 \\
\hline & 2-way significance level (sig) & & 0.000 \\
\hline $\mathrm{N}$ & 28 & 28 \\
\hline Skill performance & Pearson correlation coefficient & 0.275 & 1 \\
\hline 2-way significance level (sig) & 0.000 & \\
\hline $\mathrm{N}$ & 28 & 28 \\
\hline
\end{tabular}

As shown in Table 2, the significance level of the Pearson test is 0.000 and this level is less than the minimum level of 0.05 and also calculated according to the Pearson correlation coefficient of 0.367, and this The amount of critical mass of Sphrman with a degree of freedom of 305 , which is 197.0, is greater, therefore, psychological hardiness affects the performance of the sports skills of the Erzurum footballers.

Table 3. Analysis of variance of regression model of psychological hardiness on skill performance

\begin{tabular}{|c|c|c|c|c|c|c|}
\hline Stand error & & $\begin{array}{l}\text { Detection } \\
\text { factor } \\
\text { justified } \Delta \mathrm{R}\end{array}$ & & $\begin{array}{l}\text { Detection coefficient } \\
\left(\mathrm{R}^{2}\right)\end{array}$ & $\mathrm{R}$ & \\
\hline 14.6231 & & 0.113 & & 0.129 & 0.312 & \\
\hline Sig. & $\begin{array}{c}\text { level of } \\
\text { confidence }\end{array}$ & $\mathrm{F}$ & MS & SS & $\mathrm{df}$ & $\begin{array}{l}\text { source of the } \\
\text { changes }\end{array}$ \\
\hline 0.000 & 0.95 & & 6211.345 & 6211.345 & 1 & Regression \\
\hline Result & & 29.15 & 212.567 & 5154621.464 & 27 & Rest \\
\hline Acceptance & & & & 5321.616 & 28 & Total \\
\hline
\end{tabular}

As it is seen in Table 3 that the significance level of the corresponding test is 0000 , it can be argued that the above test 
is significant with a 0.05 error or a confidence level of 0.95 . According to the $\mathrm{R} 2$ detection coefficient, which is the ratio of the changes explained by the $\mathrm{x}$ variable to the total changes, is 113 . It can be argued that $11.3 \%$ of variations in skills performance are explained by changes in psychological hardiness

\section{Discussion and Conclusion}

The results of the research showed that psychological hardiness is effective on the performance of skills. The research is consistent with Sheard (2009), Singh (2010), Thompson (2017), Hasanvand et al. (2014). Also, among the components of hardiness, the combat component was a significant predictor of athletic performance and $3.9 \%$ of the variance Exercise explained. Although all the features considered important by the subjects and necessary for the ideal performers in terms of mental tenacity, it was necessary to change the focus of the sport or not, according to the estimates, as the last obvious case. The mental hardness has focused on elite athletes (such as athletes, athletes, athletes, or national level), and existing measurements have been made based on studies done on elite athletes. Studies on academic athletes have paid little attention and it is possible that psychological hardness tools for elite athletes would be more standard than academic athletes. The findings showed that tough athletes had better performance. Therefore, it seems that evaluating and strengthening hardiness can be used to interact with the purpose of increasing performance.

According to the WHO (2011), mental health is the perfection of physical, psychological and social well-being, and not just the absence of diseases. For this organization, mental well-being, prevention of mental illness, and the treatment and rehabilitation of people suffering from mental problems also include mental health (Eris, 2018).

In explaining this, we can point to Gibson, who stated that psychological hardiness is related to the inner point of control and self-efficacy. This intrinsic and acquired advantage over the years of experience enables performers to have outstanding self-regulation skills. Generally, those who are psychologically hard-core are more likely to be concentrated, more confident and more controllable at the time of pressure and the high level of exercise they are in. The psychological hardiness will reduce the stressful events and physical and mental arousal resulting from these events, thus leaving a positive impact on peoples' health (Sheard, Golby, 2007). Besharat (2007) demonstrated that people with high psychological hardiness handle the stressful conditions better in comparison with people with low psychological hardiness while the former group uses more effective coping strategies. The psychological hardiness protects the youth against the psychological problems and the psychological impacts of the problematic events (Pinquart, 2009). This issue will lead to a promotion of problem solving skills among people (Salehi Fadardi et al., 2010). Sheard (2009) revealed that superior mental toughness and hardiness are related to successful sport performance. Practical implications focus on the potentiality of ameliorative cultural environments.

In fact, mental hardiness is one of the characteristics of personality. The tenacity of a set consists of a personality trait that acts as a source of resistance as a protective shield in the face of stressful life events. Stiff people often find life events interesting, diverse, informative and challenging. They consider life events as realistic or with a long-term vision, and are therefore more optimistic about the whole of life's events. Perhaps there is the same optimism that makes the hardline people out of unpleasant incidents, and so on, expecting more illnesses. They consider life events as realistic or with a long-term vision, and for this reason, relative to all life events are more optimistic (Erciş, 2018).

\section{References}

Erciş, S. (2018). Effects of Physical Fitness and Mental Hardness on the Performance of Elite Male Basketball Players, Journal of Education and Training Studies, 6(9a), 56-60. https://doi.org/10.11114/jets.v6i9a.3526

Golby, J., Sheard, M., \& Van Wersch, A. (2007) Evaluating the factor structure of the Psychological Performance Inventory. Perceptual and Motor Skills, 105, 309-325. https://doi.org/10.2466/pms.105.1.309-325.

Hasanvand, B., Mohammadi, A. A., \& Rezaei, D. E. (2014). Prediction of Psychological Hardiness Based on Mental Health and Emotional Intelligence in Students, practice in clinical psychology, 2(4), 255-262.

Hystad, S. W., Eid, J., \& Brevik, J. I. (2012). Effects of psychological hardiness, job demands, and job control on sickness absence: A prospective study. Journal of Occupational Health Psychology, 16, 487-507.

Lin, Y., Mutz, J., Clough, P. J., \& Papageorgiou, K. A. (2017). Mental Toughness and individual differences in learning, educational and work performance, psychological well-being, and personality: A systematic review. Frontiers in Psychology. https://doi.org/10.3389/fpsyg.2017.01345

Maddi, S. R., Harvey, R. H., Khoshaba, D. M., Lu, J. L., Persico, M., \& Brow, M. (2006). The personality construct of hardiness, III: relationships with repression, innovativeness, authoritarianism, and performance. Journal of Personality, 74, 575-597. https://doi.org/10.1111/j.1467-6494.2006.00385.x

Newland, A., Newton, M., Finch, L., Harbke, C. R., \& Podlog, L. (2013). Moderating variables in the relationship between mental toughness and performance in basketball. Journal of Sport and Health Science, 2(3), 184-192. 
https://doi.org/10.1016/j.jshs.2012.09.002

Pinquart, M. (2009). Moderating effect of dispositional resilience on association between hassles and psychological distress. Journal of Applied Developmental Psychology, 30, 1-8. https://doi.org/10.1016/j.appdev.2008.10.005

SalehiFadardi, J., Azad, H., \& Nemati, A. (2010). The relationship between resilience, motivational structure, and substance use. Procedia-Social and Behavioral Sciences, 5, 1956-1960. https://doi.org/10.1016/j.sbspro.2010.07.395

Sheard, M. (2009). A Cross-National Analysis of Mental Toughness and Hardness in Elite University Rugby League Teams, Perceptual and Motor Skills, 109, 213-223. https://doi.org/10.2466/pms.109.1.213-223

Sheard, M., \& Golby, J. (2007). Hardiness and undergraduate academic study: The moderating role of commitment. Journal of Personality and Individual Differences, 43, 579- 588. https://doi.org/10.1016/j.paid.2007.01.006

Singh, B. H. (2010). Personality Hardness, Burnout and Sport Compitition Anxiety among Athleteics and

Thompson, C. (2017) Improving Hardiness in Elite Rugby Players, Thesis Submitted in Partial Fulfilment of the Requirements for the Degree of Doctor of Applied Psychology (Sport)

Ucan, I. (2018). The Performance of Prediction of Elite Male Trompline Based on Physical factors, Journal of Educational and Training Studies, 6(4a), 39-44. https://doi.org/10.11114/jets.v6i4a.3259

Wrestling Coaches, British Journal of Sports Medicine, 44(Suppl I), 75-82.

https://doi.org/10.1136/bjsm.2010.078725.248

\section{Copyrights}

Copyright for this article is retained by the author(s), with first publication rights granted to the journal.

This is an open-access article distributed under the terms and conditions of the Creative Commons Attribution license which permits unrestricted use, distribution, and reproduction in any medium, provided the original work is properly cited. 